\title{
Combinations of TLR Ligands: A Promising Approach in Cancer Immunotherapy
}

\author{
Saskia Stier, Claudia Maletzki, Ulrike Klier, and Michael Linnebacher \\ Department of General Surgery, Molecular Oncology and Immunotherapy, University of Rostock, Schillingallee 35, \\ 18057 Rostock, Germany
}

Correspondence should be addressed to Michael Linnebacher; michael.linnebacher@med.uni-rostock.de

Received 11 July 2013; Revised 29 August 2013; Accepted 2 October 2013

Academic Editor: Senthamil R. Selvan

Copyright (C) 2013 Saskia Stier et al. This is an open access article distributed under the Creative Commons Attribution License, which permits unrestricted use, distribution, and reproduction in any medium, provided the original work is properly cited.

Toll-like receptors (TLRs), a family of pattern recognition receptors recognizing molecules expressed by pathogens, are typically expressed by immune cells. However, several recent studies revealed functional TLR expression also on tumor cells. Their expression is a two-sided coin for tumor cells. Not only tumor-promoting effects of TLR ligands are described but also direct oncopathic and immunostimulatory effects. To clarify TLRs' role in colorectal cancer (CRC), we tested the impact of the TLR ligands LPS, Poly I:C, R848, and Taxol on primary human CRC cell lines (HROC40, HROC60, and HROC69) in vitro and in vivo (CT26). Taxol, not only a potent tumor-apoptosis-inducing, but also TLR4-activating chemotherapeutic compound, inhibited growth and viability of all cell lines, whereas the remaining TLR ligands had only marginal effects (R848 > LPS > Poly I:C). Combinations of the substances here did not improve the results, whereas antitumoral effects were dramatically boosted when human lymphocytes were added. Here, combining the TLR ligands often diminished antitumoral effects. In vivo, best tumor growth control was achieved by the combination of Taxol and R848. However, when combined with LPS, Taxol accelerated tumor growth. These data generally prove the potential of TLR ligands to control tumor growth and activate immune cells, but they also demonstrate the importance of choosing the right combinations.

\section{Introduction}

Since the last decades of cancer research, numerous approaches have been initiated aiming at activating cytotoxic immune reactions against tumors. Besides targeting the adaptive immune system, stimulators of the innate immune system gained much attention. In this context and resulting from their strong immune stimulatory capacity, ligands for Toll-like receptors (TLRs) were extensively studied. TLRs are a family of pattern recognition receptors. They have a key position in the first-line defense against pathogens by recognizing specific pathogen-associated molecular patterns, conserved structures expressed by pathogens. Furthermore, they bind to endogenous damage-associated molecular patterns. These molecules are released by stressed or dying cells [1]. Upon ligand binding, TLR-signaling leads to inflammation and antimicrobial responses, thus priming adaptive immune responses [2]. Besides components directly originating from bacteria or viruses, synthetic substances like
Poly I:C (ligand for TLR3) or Resiquimod (R848, ligand for TLR7/8) were extensively studied either as single substance in experimental cancer models or as vaccine adjuvant in clinical trials [3-5].

TLRs are primarily expressed by cells belonging to the innate immune systems' arm, that is, dendritic cells (DCs) and monocytes. The observation that TLRs are functionally expressed in several types of tumors, however, hints towards another tumor-promoting role [6]. Recent evidence suggests that they act as double-edged sword in tumorigenesis.

Even more, several studies revealed adverse effects of TLRs on carcinogenesis. Kundu et al. described LPS-induced malignant transformation of benign prostate epithelia [7]. The group of Schmaußer found that TLRs on malignant gastric carcinoma cells enabled interaction with pathogens and subsequently enhanced cell proliferation [8]. Some additional studies substantiated a tumor growth and malignancypromoting effect of TLRs overexpressed on tumor cells. These include employment of TLR 4 signaling by breast and 
colorectal cancer cells $[9,10]$, as well as flagellin-induced activation of TLR5 on gastric cancer cells [11].

On the other hand, at least as many studies revealed antitumoral effects of TLR ligands by inducing tumor cell apoptosis/necrosis or activating immune cells. Direct oncopathic effects on different tumor entities have been described for Poly I:C (TLR3 agonist) and Imiquimod (TLR7 agonist) [12-14]. Hence, similar to what is known about the immune system as a whole, TLRs are capable of both inhibiting and promoting cancer.

Although the TLR expression patterns and their effects are well understood on immune cells, their functional relevance in tumorigenesis and resulting immunological changes remain to be fully elucidated. Further studies are needed to clarify their function in tumor biology and to evaluate their therapeutic potential which will finally help to establish effective treatment schedules. Therefore, we here tested TLR ligands for treatment of colorectal carcinomas (CRC) in vitro and in vivo. Experiments revealed strongest oncolytic effects in the presence of a functional immune system. Hence, these findings underscore the rationale for using TLR ligands in cancer immunotherapy-either alone or as combinations; preferably together with conventional chemotherapy.

\section{Material and Methods}

2.1. Tumor Cell Lines and TLR Ligand Treatment. The CRC cell lines HROC40, HROC60, and HROC69 (all three microsatellite stable) were established in our lab from patients subsequent to operation and for analyses passages 25-35 were used. Cells were maintained in full medium: DMEM/HamsF12 supplemented with $10 \%$ fetal calf serum, glutamine $(2 \mathrm{mmol} / \mathrm{L})$, and antibiotics (medium and supplements were purchased from PAA, Cölbe, Germany). The cells were seeded at the appropriate density for each cell line in both 96-well or 24-well plates and incubated $24 \mathrm{~h}$ prior to TLR ligand treatment. For all in vitro experiments, the following TLR ligands and their combinations were used in the concentrations $0.01,0.1,1$, and $10 \mu \mathrm{M}$ : Taxol, R848 (Enzo Life Sciences, Lörrach, Germany), LPS (SigmaAldrich, Hamburg, Germany), and Poly I:C (InvivoGen, San Diego, CA, USA). All substances were applied once. Antitumoral effects were examined after 24,48 , and $72 \mathrm{~h}$ of incubation.

2.2. RNA Isolation, cDNA Synthesis, and Quantitative RealTime PCR. Total RNA from tumor cells was isolated with TRIzol reagent according to the manufacturer's instructions. RNA was reverse-transcribed into cDNA from $2 \mu \mathrm{g}$ RNA using the High Capacity cDNA Reverse Transcription Kit (Applied Biosystems, Foster City, CA, USA). Target cDNA levels of human cell lines were analyzed by quantitative real-time PCR using TaqMan Universal PCR Master Mix and predesigned TaqMan gene expression assays, Hs00152933_m1 (TLR3), Hs00152939_ml (TLR4), Hs00152971_ml (TLR7), Hs00152972_ml (TLR8), Hs00152973_ml (TLR9), and Hs99999905_ml (GAPDH, housekeeping gene control) in an ABI Prism 7000 sequence detection system (Applied
Biosystems). PCR conditions were as follows: $95^{\circ} \mathrm{C}$ for $10 \mathrm{~min}$, 40 cycles of $15 \mathrm{~s}$ at $95^{\circ} \mathrm{C}$, and $1 \mathrm{~min}$ at $60^{\circ} \mathrm{C}$. TLR expression by the murine CRC cell line CT26 was analyzed using SibirRoxHot Master Mix (Bioron, Ludwigshafen, Germany). The mRNA levels of target genes were normalized to GAPDH. Primer pairs used in real-time PCR were the following: TLR3 $5^{\prime}$-GGTCCCCAGCCTTCAAAGAC- $3^{\prime}$ and $5^{\prime}$-ACGAAGAGGGCGGAAAGGT-3', TLR4 5' -ACCTGGCTGGTTTACACGTC- $3^{\prime}$ and $5^{\prime}$-CTGCCAGAGACATTGCAGAA- $3^{\prime}$, TLR7 5'-CCACAGGCTCACCCATACTTC- $3^{\prime}$ and $5^{\prime}$-GGGATGTCCTAGGTGGTGACA-3', GAPDH $5^{\prime}$ CATGGCCTTCCGTGTTCCTA- $3^{\prime}$ and $5^{\prime}$-CCTGCTTCACCACCTTCTTGAT-3'. Reactions were performed in triplicate wells. The general expression level of each sample was considered by calculating $\Delta \mathrm{CT}\left(\Delta \mathrm{Ct}=\mathrm{Ct}_{\text {target }}-\mathrm{Ct}_{\mathrm{GAPDH}}\right)$. Expression patterns were classified as strong, moderate, low, or absent in comparison to normal immune cells (i.e., human dendritic cells and murine macrophages). These cells served as standard and quality control in each qRT-PCR.

2.3. MTS and Flow Cytometric Cell Viability Analysis. Experiments were performed in 96-well plates in triplicate and replicated at least three times. MTS (Promega, Mannheim, Germany) was mixed with PMS (Sigma-Aldrich) and $20 \mu \mathrm{L}$ of this mix was added to each well. After incubation of cells at $37^{\circ} \mathrm{C}$ for at least $1 \mathrm{~h}$, the absorbance was measured at $492 \mathrm{~nm}$ on a LP400 ELISA reader (Anthos Mikrosysteme, Krefeld, Germany). Direct TLR ligand effects on tumor cell viability were additionally characterized by flow cytometry. Cells were treated as described above. All cells (adherent plus cells in supernatant) were harvested and stained with $2 \mu \mathrm{M}$ Calcein-AM (Sigma Aldrich). Fluorescent microsphere beads $\left(1.4 \times 10^{5}\right.$ beads/mL, Polysciences, Germany) were added to the samples in a final volume of $200 \mu \mathrm{L}$. A gate was set in the FSC/SSC on the beads, and all living cells (CalceinAM positive) per 5.000 beads were counted. Experiments were performed in 24-well plates in duplicates and replicated at least four times. Percentages of proliferating/viable and total number of cells were calculated compared to untreated control cells, that is, without TLR ligand application. Samples were analyzed on a FACSCalibur Cytometer (BD Pharmingen). Data analysis was performed using CellQuest software (BD Pharmingen).

2.4. Lymphocyte Preparation and Coculture Experiments. Peripheral blood lymphocytes (PBL) were obtained from healthy volunteers following Ficoll density-gradient centrifugation. The cytotoxicity mediated by TLR ligand-stimulated immune cells on CRC cell lines was examined by direct coculture experiments. Tumor cells were seeded in duplicate into 24 -well plates $\left(1 \times 10^{4} /\right.$ well $)$ and incubated overnight. Medium was removed and fresh medium containing PBLs (1 $\times 10^{6} \mathrm{PBL} /$ well, ratio $\left.1: 100\right)$ with or without TLR ligand was added. Following a $48 \mathrm{~h}$ or $72 \mathrm{~h}$ incubation period, PBLs were removed and tumor cells were harvested by trypsinization. Prior to FACS analysis, fluorescent microsphere beads (1.4 $\times 10^{5}$ beads $/ \mathrm{mL}$, Polysciences, Germany) were added to the samples in a final volume of $200 \mu \mathrm{L}$. One gate was placed 
on tumor cells in the FSC/SSC to exclude lymphocytes. A second gate was set in the FSC/SSC on the beads, and all living tumor cells per 5.000 beads were counted. A representative plot is given in Figure 4(c). Data are given as $\mathrm{X}$-fold number of tumor cells compared to untreated controls with PBLs. Another control consisted of tumor cells without PBL addition.

2.5. Flow Cytometric Phenotyping of PBL. For phenotypic analysis of human PBLs, cells were harvested after TLR ligand stimulation as described before $(72 \mathrm{~h})$. Controls were incubated in complete medium without any TLR ligand. Cells were washed and stained with directly FITC-, PE-, or APC-labeled mAbs against CD3, CD4, CD8, CD16/56, CD25, CD62L, CD69, and CD71 (each $1 \mu \mathrm{g}$, ImmunoTools, Friesoythe, Germany) for $30 \mathrm{~min}$ at $4^{\circ} \mathrm{C}$. Then, cells were washed twice and resuspended in $200 \mu \mathrm{L}$ PBS. Negative controls were stained with the appropriate isotypes. Cells were analyzed by flow cytometry as described above. For each sample, 20.000 events were measured. To overcome interindividual differences between single donors, data of untreated control PBLs were set as 1 and data of TLR ligand stimulated cells were given as $\mathrm{X}$-fold increase.

2.6. In Vivo Tumor Models and Treatment Regimen. Experiments were performed on female 8-10-week-old Balb/c mice weighing $18-20 \mathrm{~g}$. Mice were bred in the university's animal facility and maintained under specified pathogen-free conditions. All animals were fed standard laboratory chow and given free access to water. Experiments were performed in accordance with the German legislation on protection of animals and the Guide for the Care and Use of Laboratory Animals (Institute of Laboratory Animal Resources, National Research Council; NIH Guide, vol. 25, no. 28, 1996). Tumor challenge was performed by subcutaneous (s.c.) injection of $5 \times 10^{6}$ CT26 cells into the right hind leg. Tumor growth was routinely controlled at least twice a week and tumor volume was estimated according to the formula: $V=$ width $^{2} *$ length * 0.52. After tumor establishment, mice were divided into experimental groups ( $n=7$ per group) each treated with one of the following substances/combinations: Taxol $(20 \mathrm{mg} / \mathrm{kg}$ bw), R848 (60 mg/kg bw), LPS ( $2 \mathrm{mg} / \mathrm{kg} \mathrm{bw})$, Irinotecan $(20 \mathrm{mg} / \mathrm{kg}$ bw), Taxol + R848, Taxol + LPS, and R848 + LPS. Treatment was performed two times a week for a total of three weeks. As control, tumor-carrying mice received equivalent volumes of PBS (saline, $n=7$ ). Tumor-carrying mice (treatment, control) were sacrificed at day 21 or when they became moribund before the tumor volume reached $2.000 \mathrm{~mm}^{3}$. Blood samples were taken on day 10 of therapy. At the end of each experiment, blood samples, tumor material, spleen, and mesenteric lymph nodes were removed from all animals for further analysis.

2.7. Flow Cytometry of Blood and Spleen Cells. Flow cytometry was performed with leukocytes from peripheral blood during and after therapy using the following fluoresceinisothiocyanate- (FITC-) and phycoerythrin- (PE-) conjugated rat anti-mouse monoclonal antibodies (mAbs): $\mathrm{CD} 3 \varepsilon$
TABLE 1: TLR expression on CRC cell lines and immune cells.

\begin{tabular}{lcccc}
\hline & TLR3 & TLR4 & TLR7 & TLR8 \\
\hline HROC40 & ++ & ++ & + & - \\
HROC60 & ++ & ++ & + & - \\
HROC69 & - & ++ & + & - \\
DC & +++ & +++ & +++ & +++ \\
CT26 & +++ & + & + & n.d. \\
Macrophages & + & +++ & +++ & n.d. \\
\hline
\end{tabular}

$\Delta \mathrm{CT}$ values were compared between cell lines and different target genes (+++ strong expression, ++ moderate expression, + low expression, - no expression, and n.d. not done).

FITC, CD62L PE (1 $\mu$ g, ImmunoTools), CD11b FITC, CD1lc FITC, CD19 FITC, CD4 PE, CD8 PE, Gr1 PE $(1 \mu \mathrm{g}$, Miltenyi Biotec, Bergisch-Gladbach, Germany), and CD166 PE (1 $\mu \mathrm{g}$ eBiosciences, Frankfurt, Germany) followed by lysis of erythrocytes (FACS Lysing Solution, BD Pharmingen). Negative controls consisted of lymphocytes stained with the appropriate isotypes (BD Pharmingen). Samples were analyzed as described above.

2.8. Statistical Analysis. All values are expressed as mean \pm SE for in vitro data and mean \pm SEM for tumor growth data. After proving the assumption of normality, differences between controls and experimental samples were determined by using the unpaired Student's $t$-test. If normality failed, the nonparametric Mann-Whitney $U$-Test was applied. The tests were performed by using Sigma-Stat 3.0 (Jandel Corporation, San Rafael, CA, USA). The criterion for significance was set to $P<0.05$.

\section{Results}

3.1. TLR Expression on CRC Cell Lines. As a starting point for this study, the expression of TLRs was analyzed by qPCR on a set of ultra-low-passage CRC cell lines established in our lab. According to the TLR ligands chosen for the subsequent functional analyses, TLR3 (Poly I:C), TLR4 (LPS, Taxol), TLR7, and TLR8 (both R848) were examined (Table 1). TLR8 was not expressed at all, TLR7 was expressed at low levels by all cell lines; TLR4 showed moderate expression in HROC40, HROC60, and HROC69 cells compared to expression patterns of DCs. Similarly, TLR3 expression varied between cells.

3.2. Direct Effects of TLR Ligands on CRC Cells. To evaluate direct effects of TLR ligands R848, LPS, Poly I:C, and Taxol on CRC cells, the three primary tumor cell lines HROC40, HROC60, and HROC69 were treated with increasing concentrations, ranging from $0.01 \mu \mathrm{M}$ to $10 \mu \mathrm{M}$. Readout was performed after 24, 48, and 72 hours using a standard MTS assay. In each experiment and at every given time point, untreated cells served as controls.

The ligands for TLR7/8 (R848), TLR4 (LPS), and TLR3 (Poly I:C) exerted no significant antiproliferative effects (data not shown and exemplary results for R848 after 72 hours in 
R848

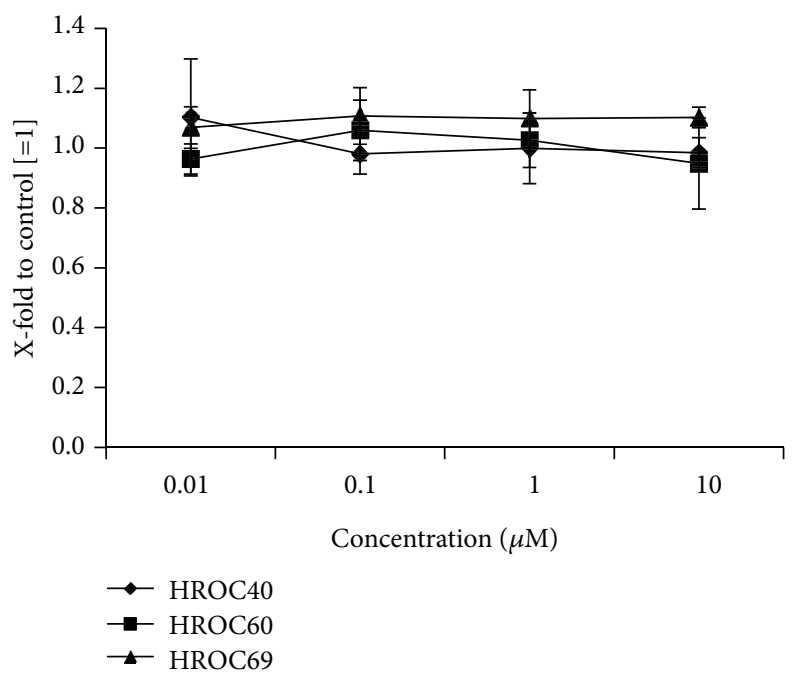

(a)

R848

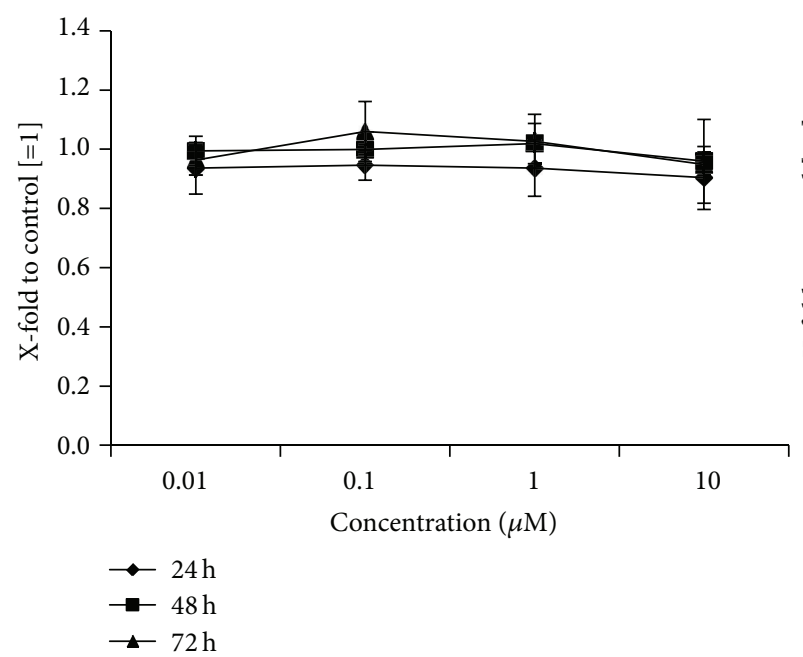

LPS

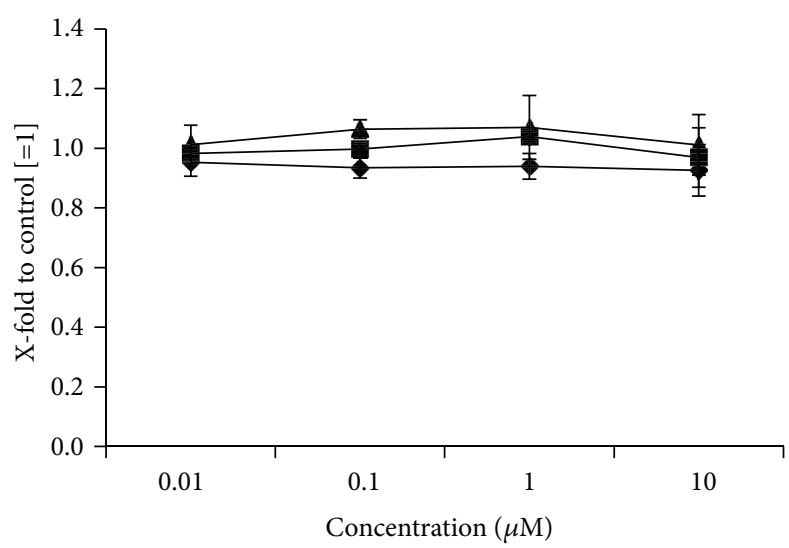

Taxol

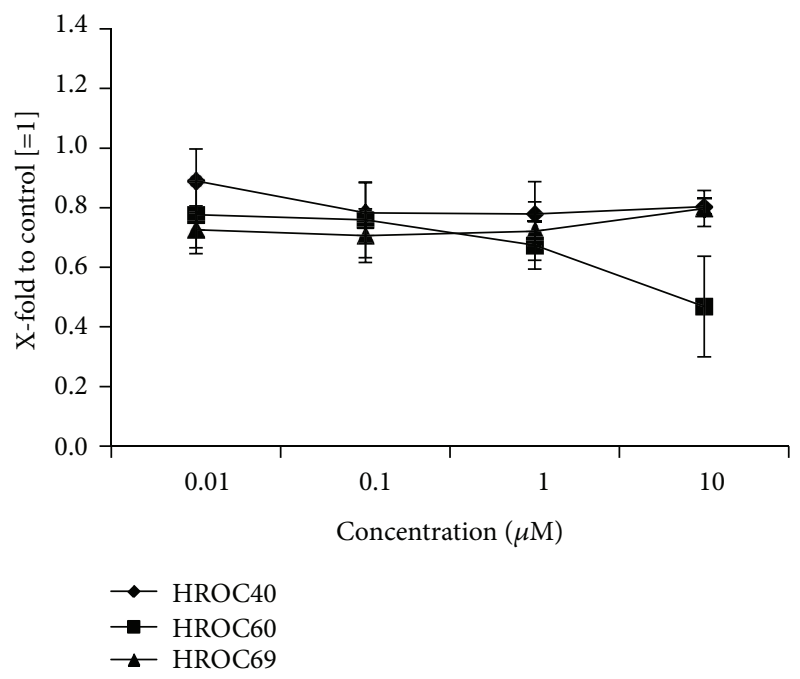

(b)

Poly I:C

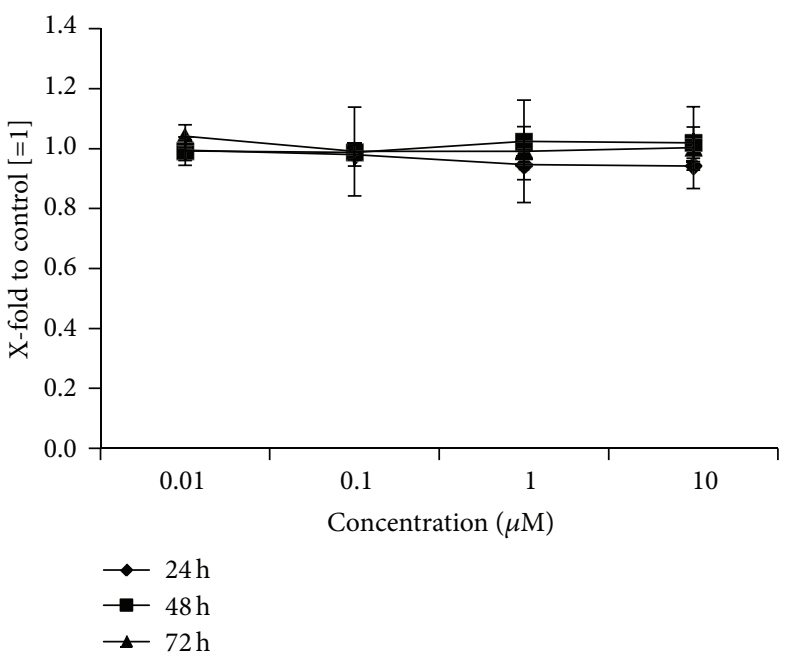

Taxol

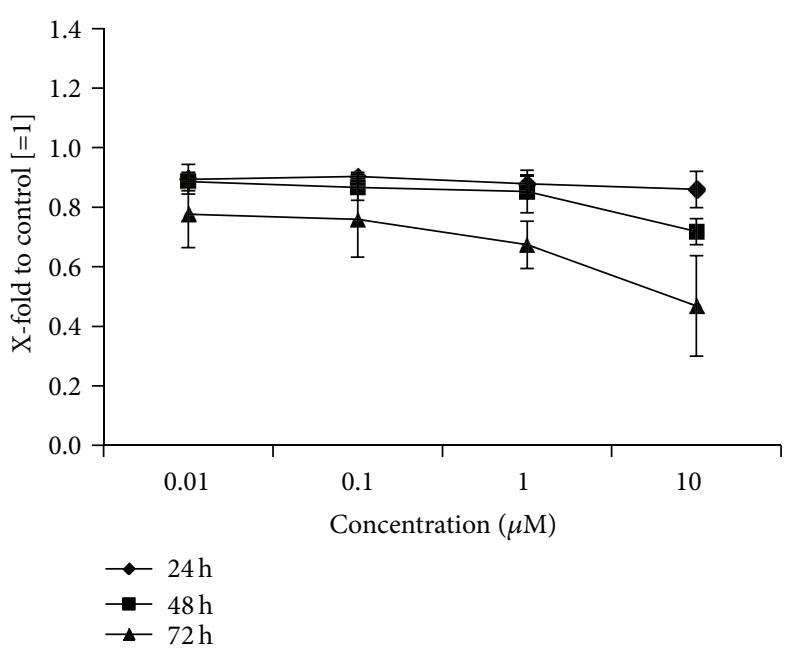

(c)

Figure 1: Continued. 


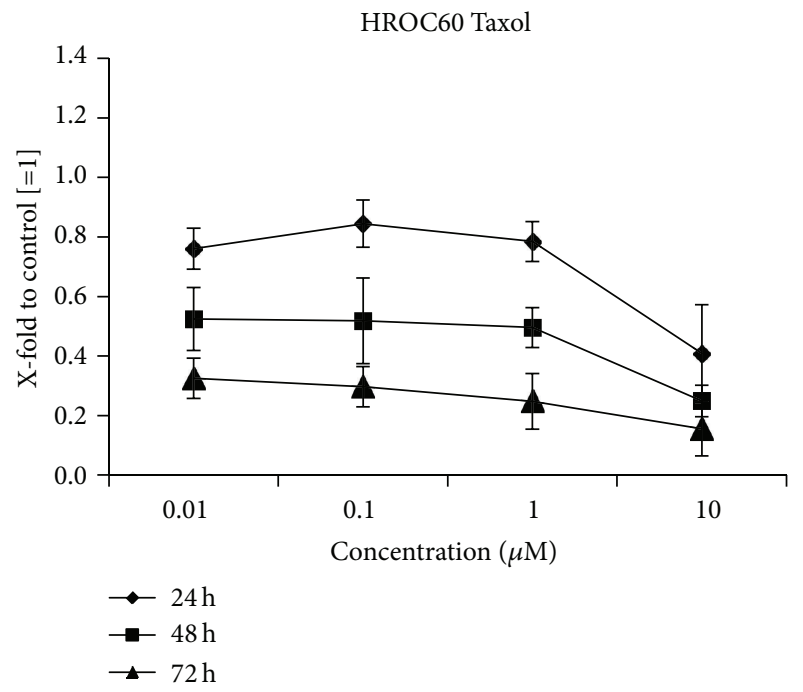

(d)

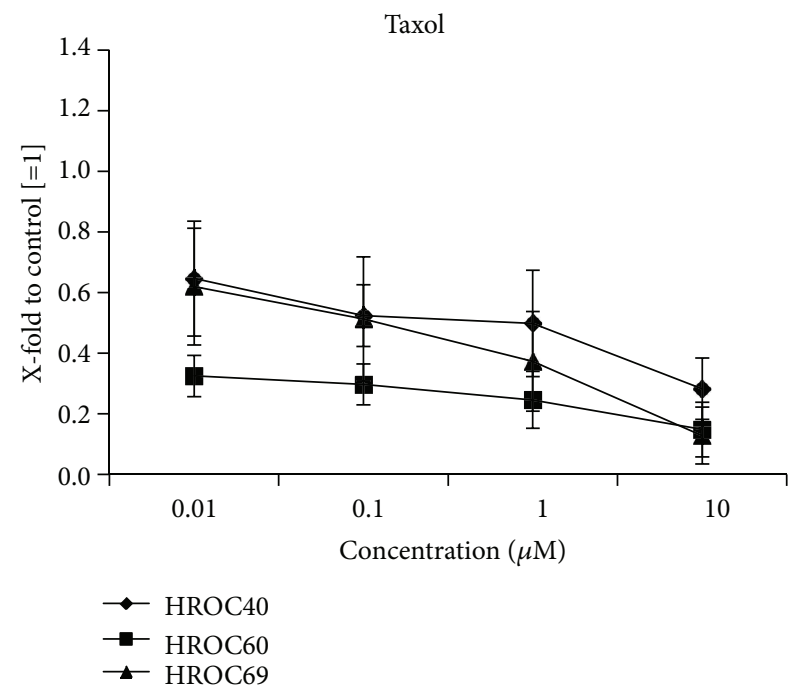

(e)

FIGURE 1: Direct cytotoxicity of TLR ligands towards CRC cell lines. Tumor cells were treated with increasing concentrations of the TLR ligands (a) R848 and (b) Taxol for $72 \mathrm{~h}$. Cell viability was assessed by standard MTS assay. Results for the HROC60 cell line reached statistical significance $(P<0.05$ versus control). (c) HROC60 cells were treated with TLR ligands for 24 , 48, and $72 \mathrm{~h}$ with different concentrations $(0.01-10 \mu \mathrm{M})$. (d) HROC60 cells were treated with Taxol for 24, 48, and $72 \mathrm{~h}$ with different concentrations $(0.01-10 \mu \mathrm{M})$. Antitumoral effects were determined by a flow cytometric assay. Given results reached significance $(P<0.05$ versus control). (e) The effect of increasing Taxol concentrations on CRC cell lines was assessed after $72 \mathrm{~h}$ incubation by flow cytometry. Results for HROC60 cells reached statistical significance at all concentrations; significant growth inhibition of HROC40 and HROC69 cells was obtained at $10 \mu \mathrm{M}$ and $1 \mu \mathrm{M}(P<0.05$ versus control). Untreated cells without TLR ligand were set as 1 and all data are given as X-fold increase. Experiments were performed in duplicate and repeated at least three times. Values are given as mean $\pm \mathrm{SD} ; P<0.05$ versus control; $t$-test.

Figure 1(a)). Taxol was the only cell growth inhibiting drug (Figure 1(b)); however, HROC40 and HROC69 displayed nearly complete resistance but in the highest dose $(10 \mu \mathrm{M})$, Taxol inhibited growth of HROC60 cells up to $>50 \%$. The metabolic activity was determined by a MTS assay and generally tended to decrease in a time- and dose-dependent manner (Figure 1(c)).

To prove these data, number and viability of CRC cells were analyzed after TLR ligand treatment by a flow cytometric assay. In principle, this test confirmed the MTS data in that Taxol was the only TLR ligand tested with direct antitumoral potential. Again, a clear time and dose dependency was observed in comparison to untreated control cells (Figure 1(d)). Antitumoral effects were generally more pronounced when compared to the results of the MTS assays. And here, Taxol exerted effects not only towards HROC60, but also against all three cell lines tested (Figure 1(e)).

To analyze if any synergism of the TLR ligands on direct antitumoral effects can be observed, all possible combinations of the substances were tested in the lowest concentration $(0.01 \mu \mathrm{M})$. Readout was again performed by flow cytometry measuring the proportion of living cells in comparison to untreated controls. The antitumoral effect of Taxol towards HROC69 and HROC60 was slightly increased by any additional substance (Figures 2 (a) and 2(b)). However, no increase could be observed for the cell line HROC40 (Figure 2(c)). Incubation with three or four substances showed no further enhancement of this effect (Figure 2).
Similar to the results of the single agents, none of the combinations without Taxol exerted any antitumoral effect on the tumor cell lines (Figure 2).

3.3. Immune Stimulation by TLR Ligands. TLR ligands exert direct immune stimulatory effects. To further elucidate their impact on PBLs in our setup, we performed a series of in vitro experiments. PBLs were either stimulated with single substances (all concentrations) or their combinations (each $0.01 \mu \mathrm{M}$ ). As expected, TLR ligands directly stimulated immune cells. In detail, most pronounced effects were observed for R848. This substance activated immune cells in a dose-dependent manner (Figure 3(a), upper panel). Numbers of $\mathrm{CD} 25^{+}$and $\mathrm{CD} 69^{+}$activated cells increased upon TLR stimulation (Figure 3(a)). Likewise, proportions of $\mathrm{CD} 16^{+} \mathrm{CD} 56^{+}$were elevated (Figure 3(b)). Hence, NK cells were identified as the main responding cell population. Poly I:C and Taxol exerted weaker though still stimulating effects, however, only at low concentrations. By contrast, LPS-mediated influences on PBLs could largely be neglected. When analyzing TLR ligand combinations, no further boost of immune stimulation was observed.

3.4. Enhancement of TLR Ligand Mediated In Vitro Effects by Lymphocytes. The above results demonstrated no effects of the TLR ligands R848, LPS, and Poly I:C but a strong influence of Taxol on CRC cells. Since the main antitumoral effects of TLR ligands are likely to base on immune stimulation, we 


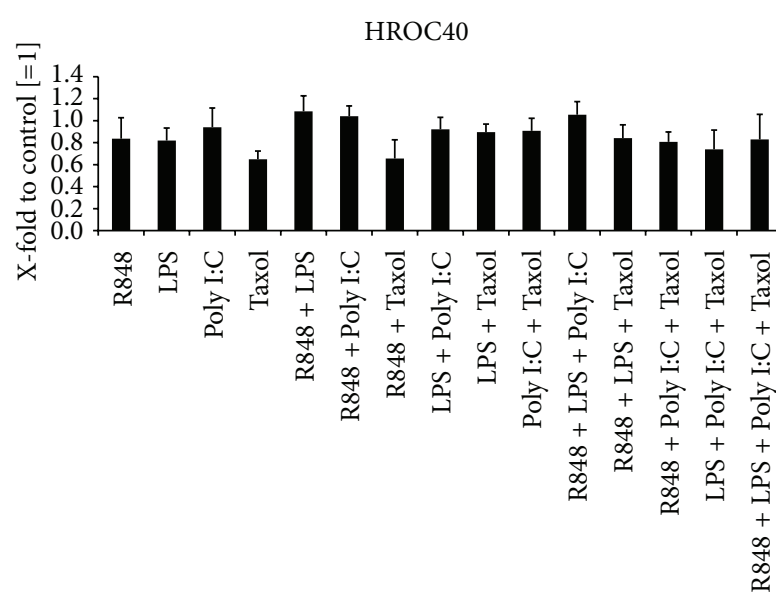

(a)

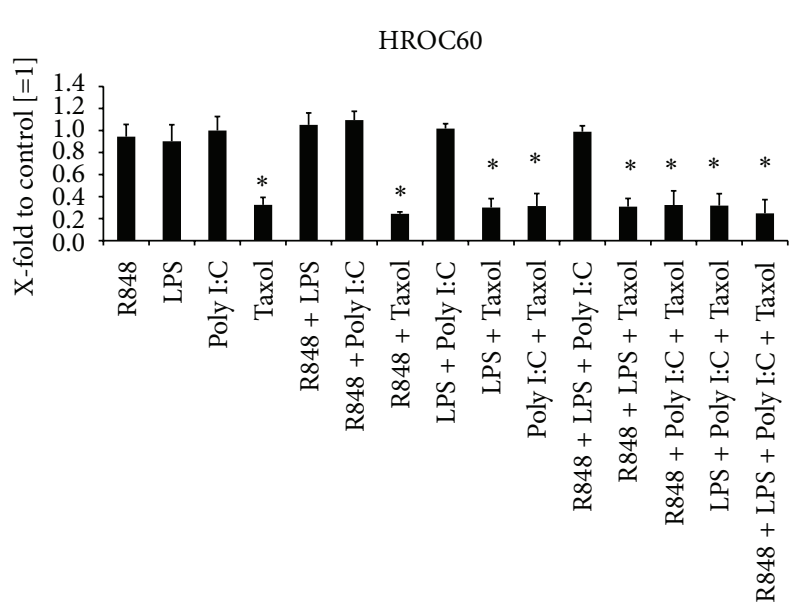

(b)

HROC69

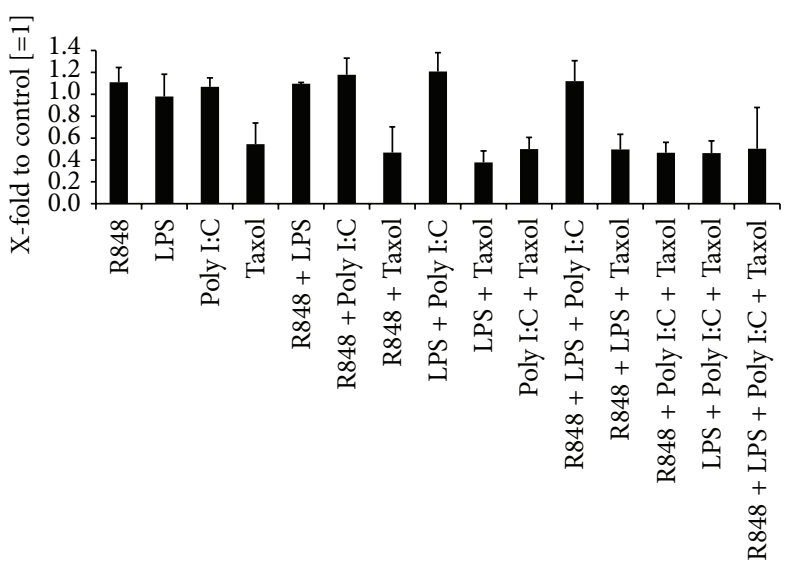

(c)

Figure 2: Direct cytotoxicity of TLR ligand combinations towards CRC cell lines. (a) HROC40, (b) HROC60, and (c) HROC69 cells were treated with all possible combinations between R848, LPS, Poly I:C, and Taxol for $72 \mathrm{~h}$ in a concentration of $0.01 \mu \mathrm{M}$. Antitumoral effects were determined by flow cytometry. Results after treatment with single TLR ligands $(0.01 \mu \mathrm{M})$ are additionally shown. Untreated cells without TLR ligand were set as 1 and all data are given as X-fold increase. Experiments were performed in duplicate and repeated at least three times. Values are given as mean $+\mathrm{SD} ; P<0.05$ versus control; $t$-test.

next analyzed the effects of TLR-stimulated immune cells on CRC cell lines. The latter were coincubated with PBL (ratio $100: 1$, PBL to tumor cell) from five healthy volunteers in the presence of TLR ligands $(0.01 \mu \mathrm{M}-10 \mu \mathrm{M})$. Tumor cells alone and together with PBL served as controls.

After 48 and $72 \mathrm{~h}$ of incubation, numbers of surviving tumor cells were determined using flow cytometry. Two of the donor's PBL showed strong reactions towards the CRC cell lines even in the absence of TLRs which must be considered as alloreactivity. Consequently, these were excluded from further analysis. Additionally, the results from the experiments without PBL addition are given to simplify comparability (Figure 4 ).

Activation of immune cells by R848 resulted in strong cytotoxicity towards HROC69 (76\%-93\% killing versus control (tumor cells + PBL); Figure 4(a)). In this setting, a strong dose dependency could be observed with favorable effects in higher concentrations (data not shown). The CRC cell line HROC60 was moderately affected by R848 while HROC40 showed no susceptibility to immune-mediated antitumoral effects. The TLR ligand LPS exerted no effect on tumor cells in this coculture experiment. Poly I:C treatment led to reduced cell numbers when incubated with PBL and HROC69 (versus control: tumor cells $+\mathrm{PBL}$ ). Interestingly, addition of PBL to tumor cells in the presence of the chemotherapeutic agent Taxol mediated strong oncopathic effects (Figure 4(a)). Numbers of surviving tumor cells fell to 5\% compared to the control (tumor cells $+\mathrm{PBL}$ ), and hence this coculture setting even enhanced the strong cytotoxic effects achieved by monotherapy (for comparison, please see Figure 1(d)).

Taken together, these data indicate elevated antitumoral effects by TLR ligands due to immune cell stimulation. However, tumor-cell-specific differences in vulnerability towards immune-mediated lysis were aparent. Taxol was the only substance leading to appreciable levels of cell number reduction for all cell lines.

Next, combinations of TLR ligands were added to tumor and immune cells. To identify potential synergistic effects, all 

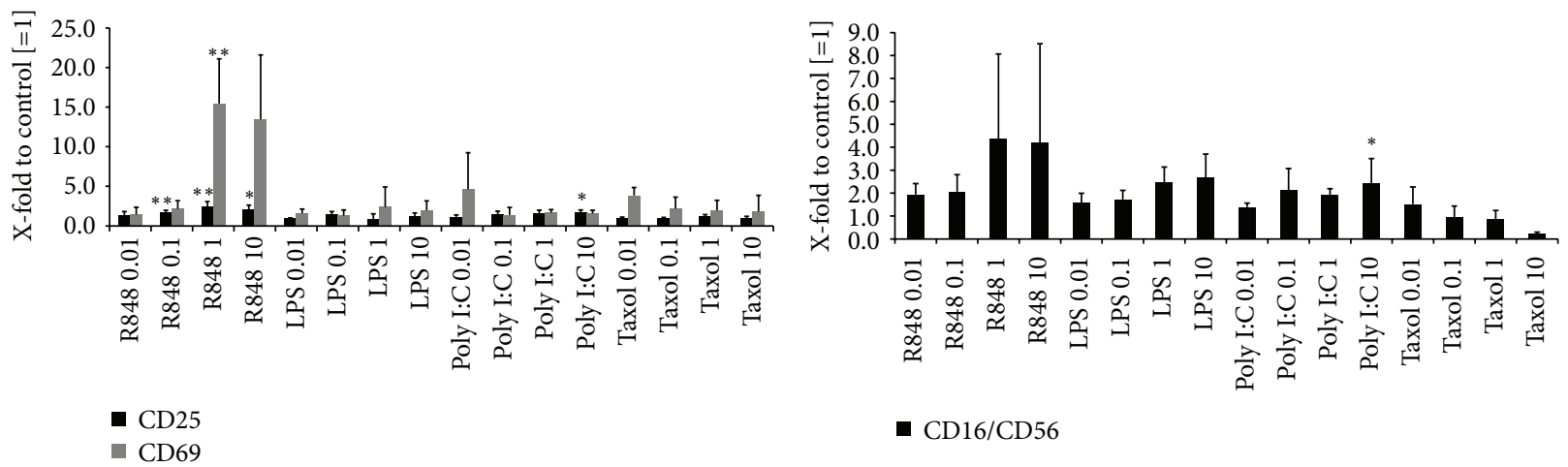

- CD16/CD56

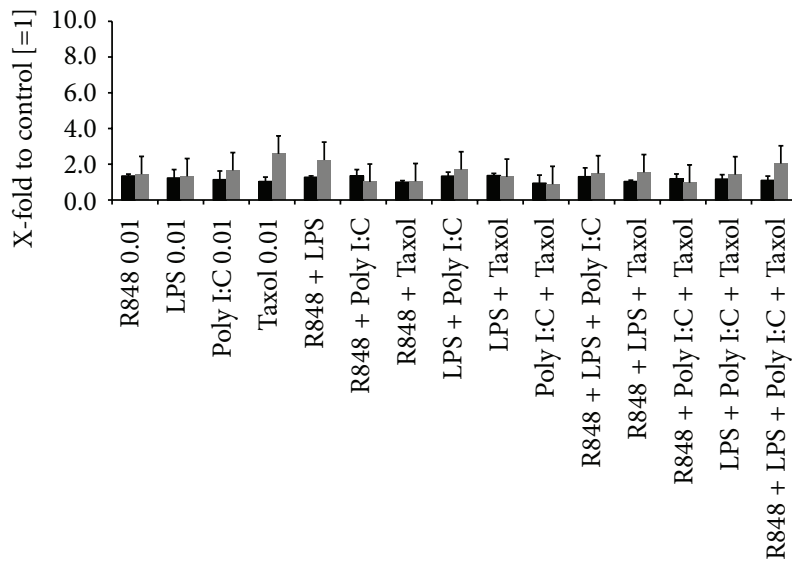

- $\mathrm{CD} 25$

CD69

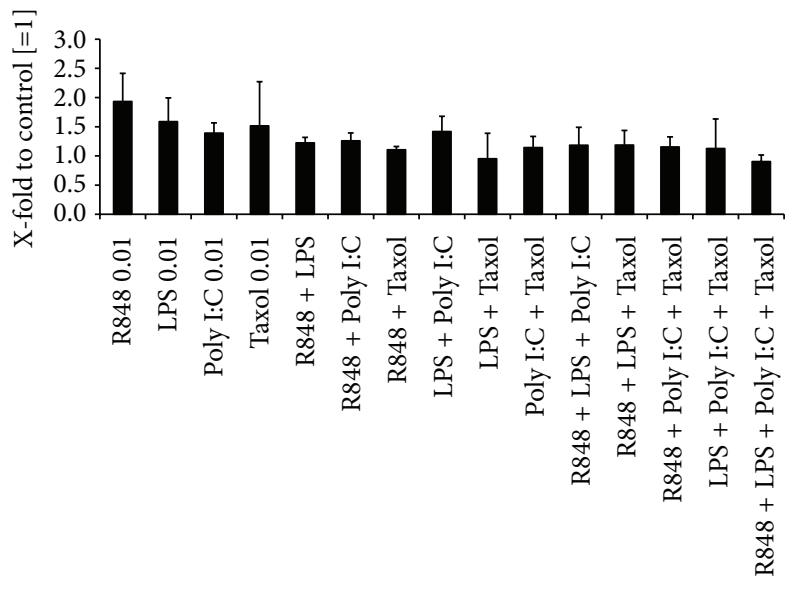

- CD16/CD56

(a)

(b)

FIGURE 3: Flow cytometric phenotyping of TLR ligand stimulated PBLs. PBLs were either incubated with single TLR ligands (0.01 $\mu$ M; (a) and (b) upper panel) or in the presence of TLR ligand combinations ( $0.01 \mu \mathrm{M}$; (a) and (b) lower panel) for $72 \mathrm{~h}$. (a) Activation of PBLs following TLR stimulation as given by positive staining for CD25 and CD69. (b) $\mathrm{CD} 16^{+} \mathrm{CD} 56^{+} \mathrm{NK}$ cells were the main responding cell population. Data of untreated control PBLs were set as 1 and all data were given as $\mathrm{X}$-fold increase. Values are presented as mean $+\mathrm{SD} ; P<0.05$ versus control; $t$-test.

possible TLR ligand combinations were considered (concentration of each TLR ligand: $0.01 \mu \mathrm{M})$. Exemplary results are given in Figure 4(b). In this setting, most pronounced effects were obtained after Taxol/Poly I:C treatment, which was, however, comparable to Taxol monotherapy. Hence, TLRcombinations did not enhance immune-mediated oncolysis. By contrast, some combinations even tended to dampen antitumor responses (e.g., R848 + Poly I:C).

3.5. Impact of TLR Ligands on CRC Tumor Growth In Vivo. To finally prove the antitumoral effects of TLR ligands on CRC, an in vivo experiment was performed using the wellestablished CT26 tumor model. In vitro, this murine CRC cell line was sensitive towards Taxol but to no other TLR ligand used in this study (data not shown).

When tumors reached $50-100 \mathrm{~mm}^{3}$, experimental treatments were performed by biweekly i.p. applications of Taxol, R848, LPS, or TLR combinations (Figure 5). In order to better appraise TLR-mediated growth inhibition in this model, one group of animals was treated with the topoisomerase I inhibitor Irinotecan, a clinically approved drug that is standard to treat CRC patients. Control mice received equivalent volumes of the solvent alone (saline).

All treatment protocols, except two (Poly I:C and the combination of Taxol + LPS), mediated at least slight growth inhibition. R848 had strongest antitumoral potential within the TLR ligand monotherapy groups (compared to Taxol > LPS, versus control). Rather unexpectedly, Poly I:C exhibited a very strong tumor growth promoting activity and animals had to be redeemed by suffering at day 7 of therapy. The strongest antitumoral effects were obtained following Taxol and R848 therapy. This combination was even better in controlling tumor growth than Irinotecan. The combination of R848 + LPS slightly prevented tumor growth. However, no additive or synergistic effects could be obtained compared to single LPS or Taxol therapy.

3.6. Correlation of Immune Status with Course of Tumor Growth. Finally, the involvement of the immune system in 

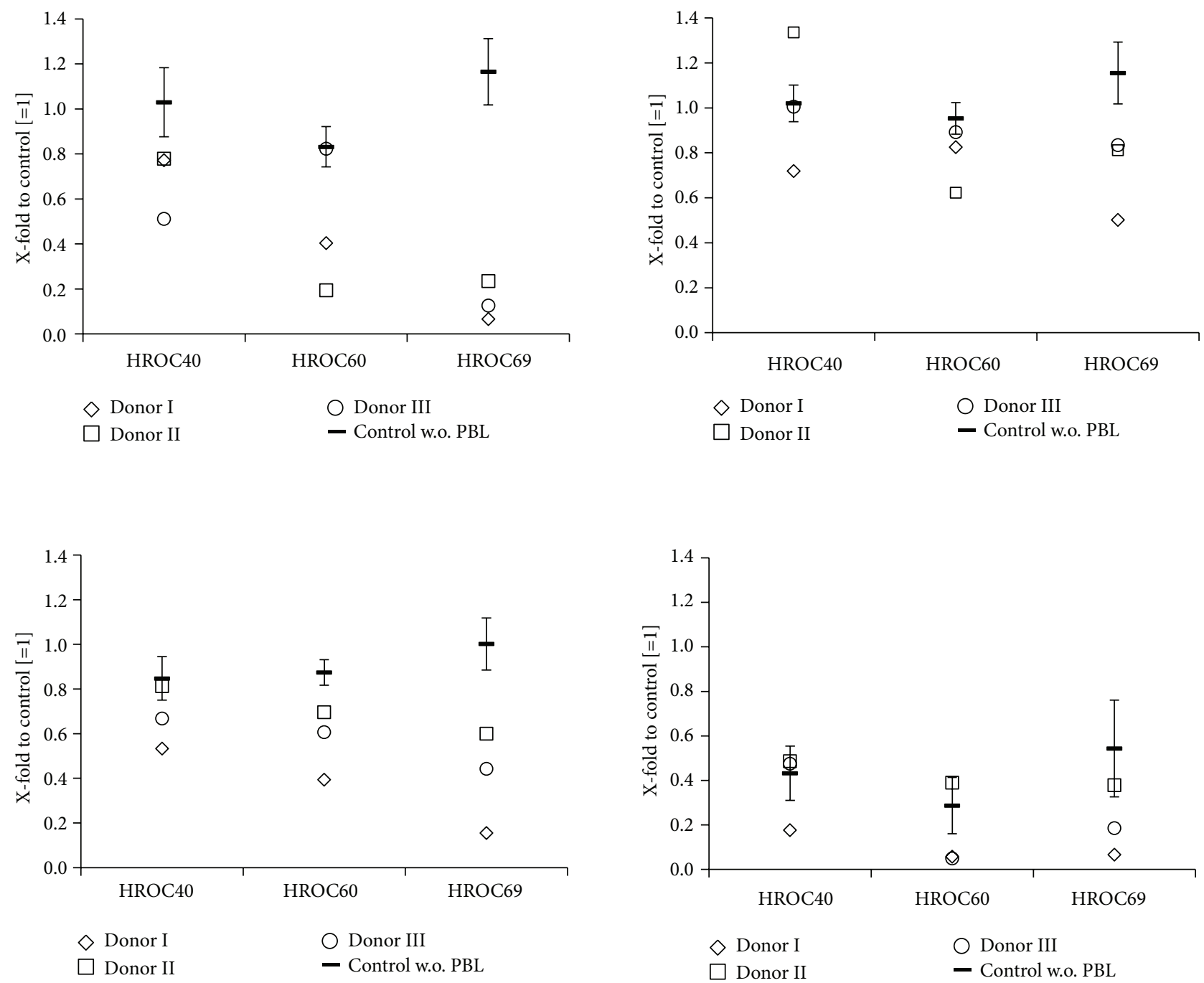

$\begin{array}{ll}\diamond \text { Donor I } & \bigcirc \text { Donor III } \\ \square \text { Donor II } & - \text { Control w.o. PBL }\end{array}$

(a)

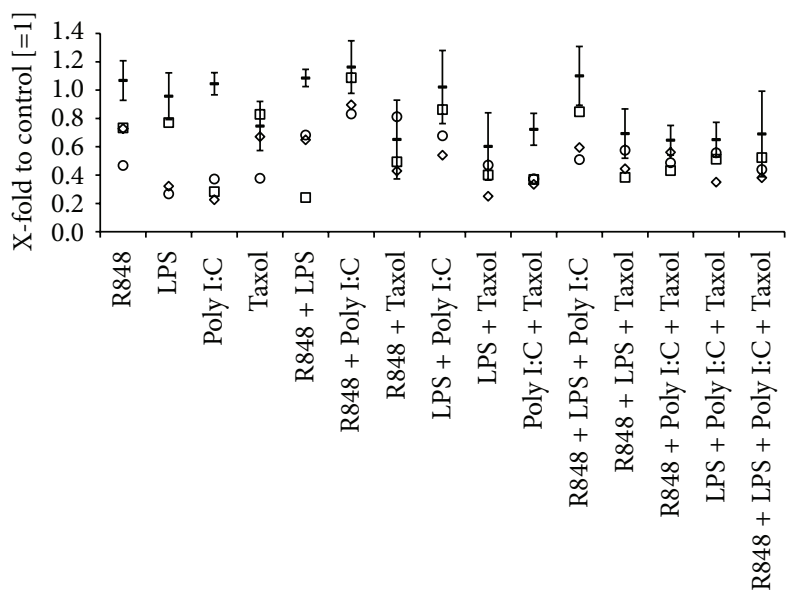
$\diamond$ Donor I
- Donor III
口 Donor II
- Control w.o. PBL

(b)

FIgURE 4: Continued. 

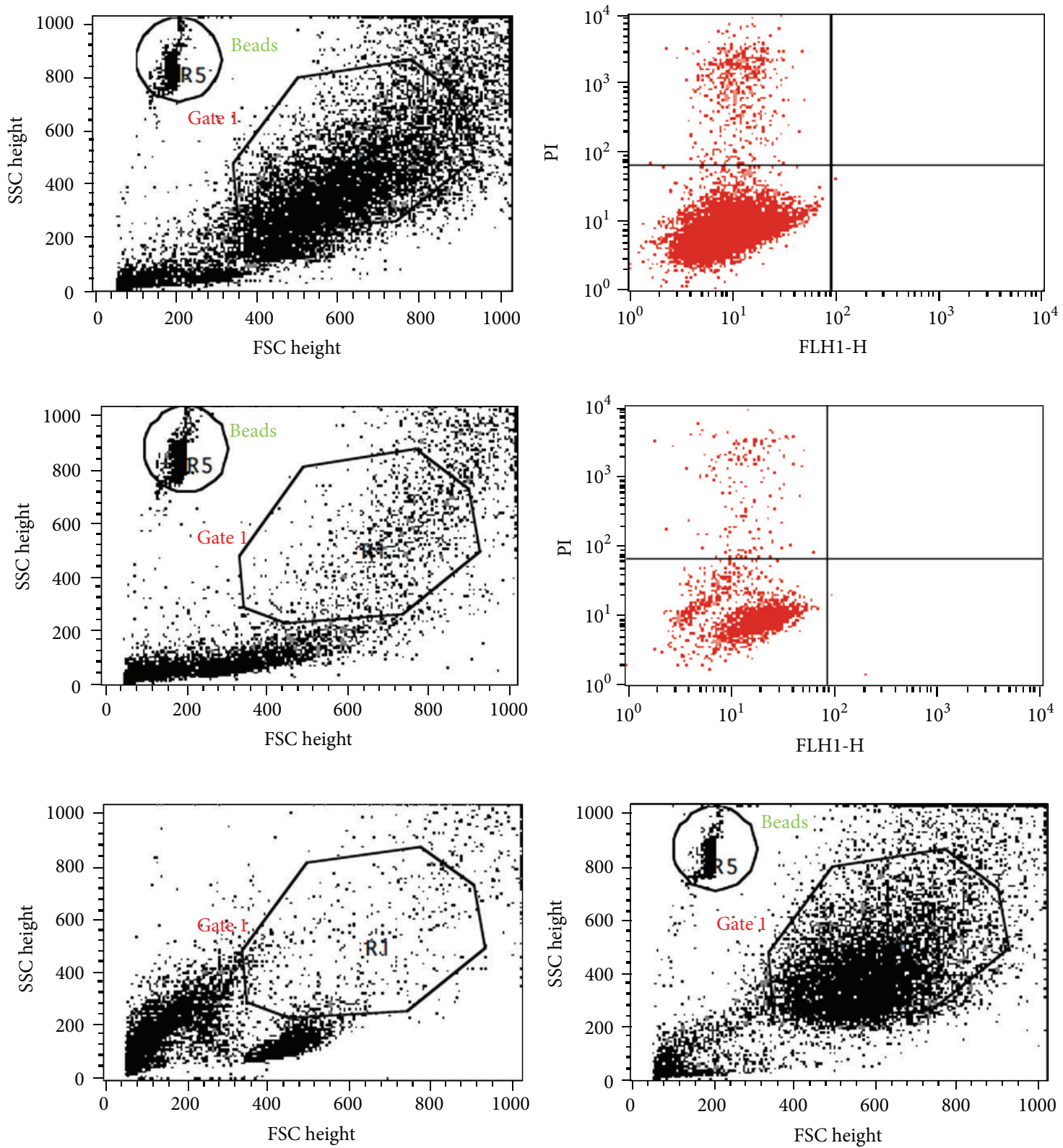

(c)

FIGURE 4: Coculture experiments. Tumor cells were cocultured with PBLs of three different healthy donors in the presence of (a) single TLR ligands $(10 \mu \mathrm{M})$ or in the presence of (b) TLR ligand combinations $(0.01 \mu \mathrm{M})$ for $72 \mathrm{~h}$. Thereafter, numbers of viable tumor cells were quantified by flow cytometry using microsphere beads as calibrator. Tumor cells without TLR ligand were set as 1 and all other data were given as Xfold increase. (b) Results for single substance treatment $(0.01 \mu \mathrm{M})$ are additionally shown. ((a), (b)) For each approach, cells treated with the particular TLR ligand but without PBL are shown. (c) Representative dot plot illustrating the gating strategy for quantification of tumor cells. Shown are FACS data of HROC69 cells treated with PBL alone (control, upper panel) and treated with PBL + R848 (10 $\mu \mathrm{M}$, middle panel) for $72 \mathrm{~h}$. Dead cells present in the gated tumor cells (Gatel) were excluded by staining with propidium iodide ( $\mathrm{PI}^{+}$cells; upper left quadrant in the right upper and middle blots). To illustrate the reliability of the gating-based separation of tumor cells and lymphocytes after coculture, FACS data of PBL alone and HROC69 cells alone are shown in addition (lower panel).

tumor growth control in vivo was examined. Blood samples from treated and control animals were analyzed on day 10 after start of therapy (Figure 6(a)) and upon therapy completion at day 17 (Figure 6(b)). Additionally, potential activation of immune cells in spleens of treated animals was studied (Figure 6(c)).
None of the treatment protocols mediated significant immunological changes, except for a massive increase in activated circulating $\mathrm{CD} 166^{+}$(ALCAM) immune cells accompanied by decreased levels of CD62L (L-selectin) cells. Especially significant elevations of $\mathrm{CD} 166^{+}$cells could be observed in the blood after 10d for treatment with Irinotecan 


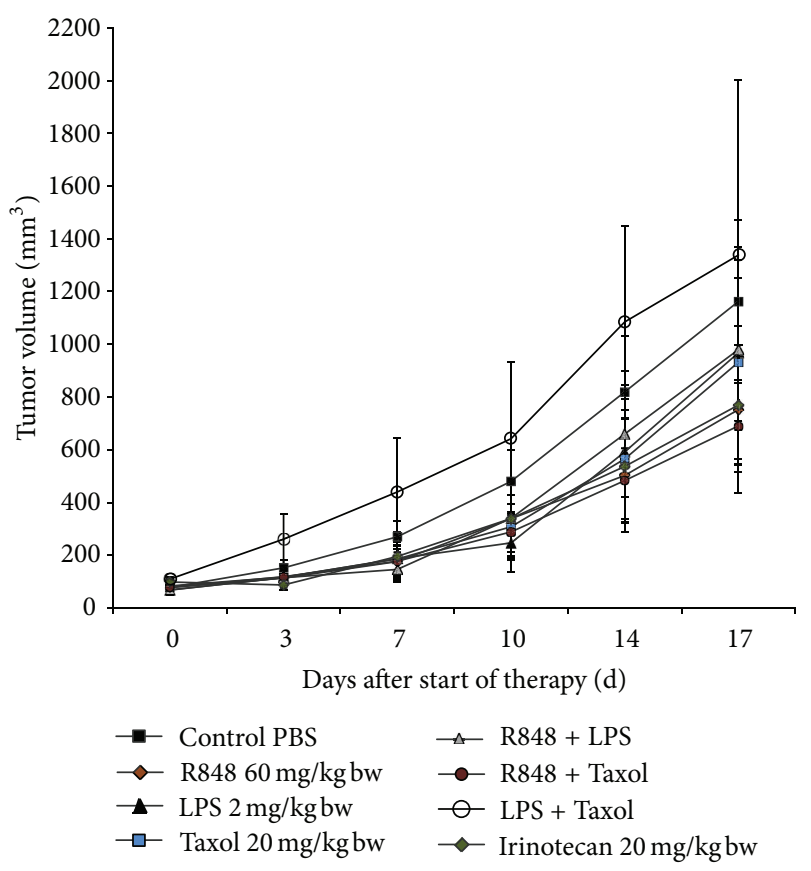

FIGURE 5: Tumor growth control in vivo. Growth kinetics of CT26 tumors in animals following injection of TLR ligands, their combinations, or Irinotecan. Therapy was performed by repetitive i.p. application of substances twice a week for a total of six times $(n=7)$. Control animals received equivalent volumes of PBS $(n=7)$. Values are given as mean \pm SEM. None of the treatments reached statistical significance ( $P$ values d17 versus control: R848 0.232; Taxol 0.655; LPS 0.705; Irinotecan 0.340; R848 + Taxol 0.252; R848 + LPS 0.680; Taxol + LPS 0.789).

$(P=0,032)$ and R848 + LPS $(P=0,035)$ as well as for LPS $(P=0,004)$ at day 17 in the spleen. Additionally, CD62L elevation achieved significance at day 17 in the spleen for the treatment groups R848 + Taxol $(P=0,002)$ and Taxol + LPS $(P=0,038)$. Both markers indicate T-cell activation. In case of L-selectin, proteolytic cleavage of cell surface molecules (=L-selectin shedding) or downregulation on the mRNA level possibly explains this observation best. Interestingly, this finding correlates with the antitumoral in vivo results, indicating involvement of these cell populations in tumor growth control.

However, we did not observe any other immune stimulatory effects at the given time points.

\section{Discussion}

In recent years, the old concept of fighting tumors with microbial agents has been rekindled by us and others [1520]. This idea is to induce tumor regression both by direct oncolysis and indirectly through immune stimulation. To develop the approach further, we here explored the potential of defined TLR ligands as therapeutic agents. Therefore, we chose ligands for TLR3 (Poly I:C), TLR4 (LPS, Taxol), TLR7, and TLR8 (both R848). Those TLR ligands underwent extensive clinical investigations, clinical investigations. However, most studies focused on the immunostimulatory capacity of these molecules and their application as adjuvants along with tumor and virus vaccines [21-23]. Mechanistically, TLR ligands exert their antitumoral effect via activation of several cell types, including DCs and T cells $[24,25]$. Due to their supposed direct antitumoral potential, TLR ligands are now tested as immunotherapeutic agents as well [26].

First, expression of relevant TLR receptors was analyzed on our freshly established, ultra-low-passage CRC tumor cell lines. Though expression pattern differed between cell lines, three out of the four receptors were detected (TLR3, 4, and 7). As expected, expression levels were comparably low (i.e., versus immune cells). By using cell lines in low passage $(<40)$, most characteristics of primary tumor cells are retained. In those, varying TLR patterns have been found not only among normal/neoplastic cells (e.g., upregulation of TLR3/4 in tumors), but also within a single tumor [27]. However, this implies an important albeit unclarified role of TLRs in CRC biology. Therein, TLR expression is special, since the colon is continuously subjected to bacterial antigens and live bacteria. There is a fine line between physiological homeostasis of the commensal flora and stimulating tumor growth under conditions of chronic inflammation [28].

To shed light on the direct effect of TLR activation, primary CRC cells were here treated with the respective TLR ligands. Those were applied as single agents or in combinations to (i) mimic whole bacteria/viruses and (ii) to analyze if any synergisms in antitumoral action can be achieved. None of the employed substances mediated significant growth inhibition or tumor apoptosis/necrosisneither as single agent nor in combination-some of them even tended to promote tumor growth (e.g., R848 + LPS; Figures 1 and 2). The sole exception was Taxol, a widelyused chemotherapeutic drug that additionally binds to TLR4. This finding is somehow interesting, since TLR4 expression often correlates with chemoresistance and metastasis [29]. Though we also observed interindividual differences, all cell lines responded to this drug (Figure 1). Antitumoral effects were slightly enhanced by adding another TLR ligand (Figure 2). However, combinations without Taxol did not mediate growth inhibition. This observation fits well with recent data from the literature. Emerging evidence suggests a dual role of TLR ligands, in which they simultaneously trigger both pro- and antitumoral effects depending on the applied molecule $[7,12,13,30]$. In multiple myeloma cells, induction of autocrine interleukin-6/-18 production accounts for enhanced proliferation upon TLR activation [30, 31]. O'Leary and coworkers even described increased metastatic potential of colon cancer cells upon LPS stimulation via Noxlmediated redox signaling [32]. By contrast, flagellin-induced TLR5 activation mediates tumor regression [33].

Despite their conflicting direct effects on tumor cells, TLR ligands are, to the most part, potent immune stimulators. In line with this well-established fact, we here observed boosted antitumoral effects in an in vitro coculture setting resembling aspects of a competent immune system (Figure 3). Effects were cell-line and substance specific-HROC40 cells generally tended to be more resistant than the other cell lines. Of note, R848 and Taxol proved most effective in stimulating immune-mediated tumor cell lysis, while LPS and Poly 

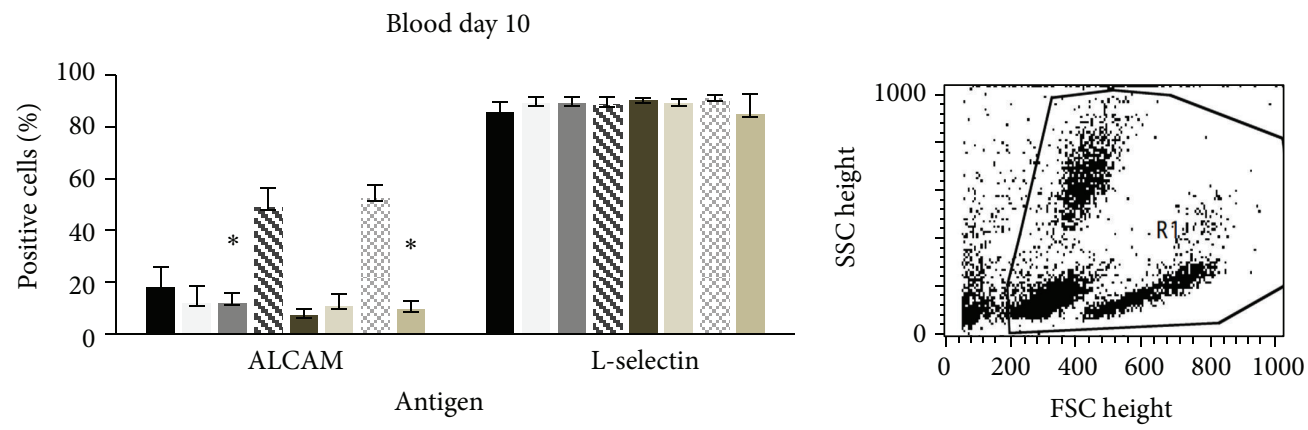

(a)
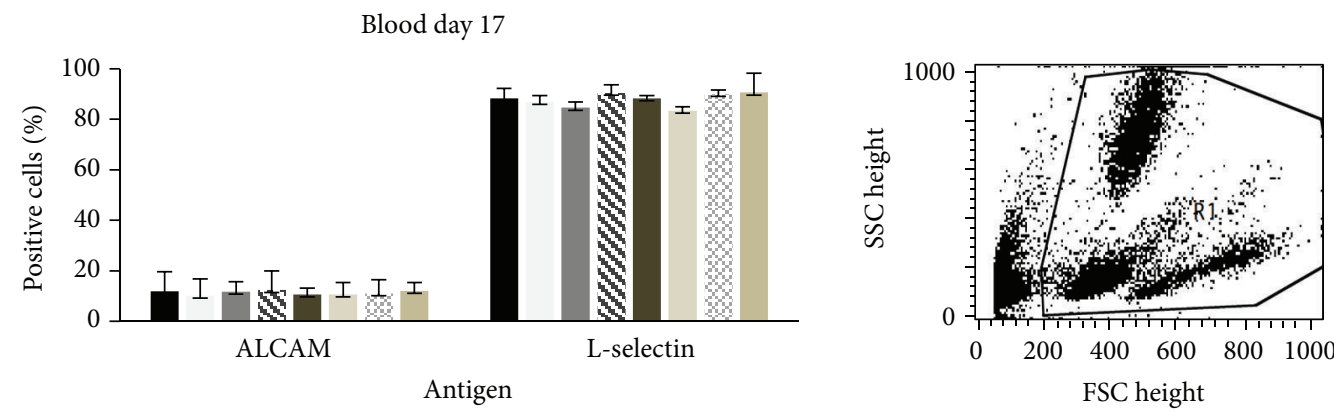

(b)
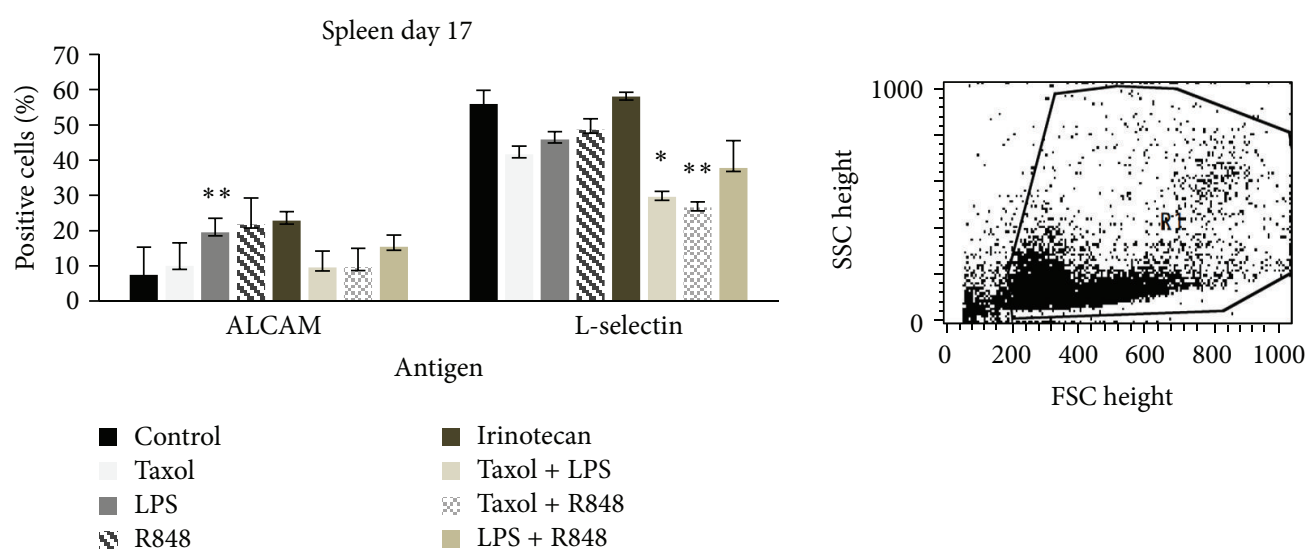

(c)

Figure 6: Analysis of leukocytes (a) during therapy and ((b), (c)) after necropsy from Balb/c mice. Blood samples of animals were taken on day 10 after start of therapy. At necropsy, blood samples and spleens were obtained and analyzed by flow cytometry. Given are the percentages of CD166 and CD62L positive cells. Control animals received equivalent volumes of PBS $(n=7)$. Values are given as mean + SD; $P<0.05$ versus saline; $t$-test. Significant data for CD166 (ALCAM) were achieved in the blood at d10 in animals treated with Irinotecan $(P=0.032)$ and R848 + LPS (0.035) and additionally in the spleen at d17 in the LPS group $(P=0.004)$. For CD62L (L-Selectin), significance was reached in the spleen at $\mathrm{d} 17$ for R848 + Taxol $(P=0.002)$ and Taxol + LPS $(0.038)$.

I:C did not work in our hands. Their supposed immunestimulating potential was presumably not strong enough to negotiate the tumor cells' natural immunosuppressive capacity [34].

The TLR7/8 activator R848 is clinically approved for immunotherapy of skin tumors [35]. In patients, R848 treatment induces inflammatory cytokine secretion by macrophages and myeloid DCs as well as IFN- $\alpha$ release by plasmacytoid DCs [36]. Additional mechanisms include activation of NK cells. Besides, Taxanes mediate immunostimulatory effects against neoplasms, supporting the idea of a TLR ligand tumor vaccine. Experiences gathered in clinical studies demonstrated that Taxol enhances NKand lymphokine activated killer cell functions [37]. The observed oncolytic effects in the present study were most likely also due to activation of NK or NK-like cells, whose tumor attacking potential is widely accepted [38-40].

To test this theory, immunotherapy with TLR ligands was performed in a syngeneic tumor model. Mice challenged with murine CT26 tumor cells received repetitive injections 
of TLR ligands. The route of application and intervals of treatment have been found to be crucial for an effective therapeutic schedule [36]. Topical application of TLR ligands is usually highly effective, whereas their systemic application met with limited success [41, 42]. However, for potential clinical application in CRC patients, systemic, repetitive injection is the method of choice. With this regimen, we observed at least partial growth retardation in our tumor model (Figure 4). Of note, monotherapy with R848 was as effective as Irinotecan, a first- and second-line standard therapeutic for advanced or recurrent CRCs [43]. The best combination used here was made of Taxol and R848, yielding $>50 \%$ growth inhibition. Antitumoral effects were accompanied by massively increased levels of activated circulating $\mathrm{CD}_{166^{+}}$immune cells, that is, activated $\mathrm{T}$ cells and monocytes (Figure 5). This finding is consistent with the in vitro coculture results on human CRC and immune cells. Based on these in vitro findings, far better antitumoral results may be expected when testing this treatment approach in humanized mice, since TLRs are differently expressed in mice and humans [44]. This was also true for our human and mouse CRC cell lines. The exact mechanism of how Taxol and R848 act complementary and mutually reinforce antitumoral responses remains elusive. One may speculate that Taxol primarily inhibits direct tumor growth by interfering with the cell cycle. R848 on the other hand stimulates the immune system (primarily CD166 ${ }^{+}$ cells). Both agents boost antitumoral immune responses that finally control tumor growth.

A rather unexpected finding of the current study was the tumor-promoting activity of Poly I:C and the combination of Taxol + LPS. This was evident from the beginning of therapy. Tumors rapidly grew, became necrotic, and tended to ulcerate. In case of Taxol + LPS, this may best be explained by some kind of antagonism, in which both substances compete for the same TLR or intracellular signaling. Also, tumor or immune cells may respond with secretion of tumor-growthpromoting and immunosuppressive cytokines (e.g., IL10) [45]. These mechanisms abrogate the antitumoral effects of the single substances and strengthen tumor development.

Therefore, TLR tolerance, characterized by a state of immune unresponsiveness, can be waived [36]. Moreover, since this was in contrast to the in vitro results, we can only speculate that the reasons for fostering of in vivo tumor growth by combinatorial treatment with these agents lie in the specific inter- and intracellular environment or may partly be attributable to the differences between human and mouse TLRs.

Lastly, though TLR ligands are critical for first-line tumor therapy, there are many arguments in favor for their immunotherapeutic application: (i) single substances or combinations are ideal immune stimulators: both antigenpresenting (especially DCs) and effector cells $\left(\mathrm{CD}^{+} \mathrm{T}\right.$ and NK cells) are functionally activated; (ii) conjugation to antigenic peptides is technically easy to perform; (iii) antibodymediated cellular cytotoxicity is enhanced by increasing Fc- $\gamma$ receptor expression; and thus treatment with monoclonal antibodies might be improved; and (iv) given their synthetic nature, they can be produced under GMP conditions and as a matter of fact, most ligands are already clinically approved.

\section{Conclusion}

Data presented herein prove the therapeutic potential of TLR agonists mediating both tumor inhibition and activation of immune effectors. Thus, they are very promising candidates for optimization of immune-based therapies, including applications as single agents or in combinations for active unspecific therapies, adjuvant standard regimens or in addition to cell-based immunotherapies. Our data also concern the Janus face character of TLR agonists and subsequent studies will further elucidate the exact balance between pro- and antitumoral activities of TLR agonists as single agents but especially of combinations.

\section{Abbreviations \\ PBL: Peripheral blood lymphocytes \\ TLR: Toll-like receptor \\ CRC: Colorectal carcinoma \\ DC: Dendritic cell.}

\section{Authors' Contribution}

Saskia Stier and Claudia Maletzki contributed equally to this work.

\section{References}

[1] G. Y. Chen and G. Nuñez, "Sterile inflammation: sensing and reacting to damage," Nature Reviews Immunology, vol. 10, pp. 826837, 2010.

[2] A. Iwasaki and R. Medzhitov, "Toll-like receptor control of the adaptive immune responses," Nature Immunology, vol. 5, no. 10, pp. 987-995, 2004.

[3] L. Chen, Y. Y. Xu, J. M. Zhou, Y. Y. Wu, Y. Y. E Q, and Y. Y. Zhu, "TLR3 dsRNA agonist inhibits growth and invasion of HepG2. 2. 15 HCC cells," Oncology Reports, vol. 28, no. 1, pp. 200-206, 2012.

[4] M. P. Schön and M. Schön, "TLR7 and TLR8 as targets in cancer therapy," Oncogene, vol. 27, no. 2, pp. 190-199, 2008.

[5] M. A. Tomai, R. L. Miller, K. E. Lipson, W. C. Kieper, I. E. Zarraga, and J. P. Vasilakos, "Resiquimod and other immune response modifiers as vaccine adjuvants," Expert Review of Vaccines, vol. 6, no. 5, pp. 835-847, 2007.

[6] E. Y. So and T. Ouchi, "The application of toll like receptors for cancer therapy," International Journal of Biological Sciences, vol. 6, no. 7, pp. 675-681, 2010.

[7] S. D. Kundu, C. Lee, B. K. Billips et al., "The toll-like receptor pathway: a novel mechanism of infection-induced carcinogenesis of prostate epithelial cells," Prostate, vol. 68, no. 2, pp. 223 229, 2008.

[8] B. Schmaußer, M. Andrulis, S. Endrich, H. Müller-Hermelink, and M. Eck, "Toll-like receptors TLR4, TLR5 and TLR9 on gastric carcinoma cells: an implication for interaction with Helicobacter pylori," International Journal of Medical Microbiology, vol. 295, no. 3, pp. 179-185, 2005.

[9] X. Tang, Y. Zhu, B. Wei, and H. Wang, "Expression and functional research of TLR4 in human colon carcinoma," American Journal of the Medical Sciences, vol. 339, no. 4, pp. 319-326, 2010. 
[10] M. Zaks-Zilberman, T. Z. Zaks, and S. N. Vogel, "Induction of proinflammatory and chemokine genes by lipopolysaccharide and paclitaxel (Taxol) in murine and human breast cancer cell lines," Cytokine, vol. 15, no. 3, pp. 156-165, 2001.

[11] E. Song, M. Kang, Y. Kim et al., "Flagellin promotes the proliferation of gastric cancer cells via the Toll-like receptor 5," International Journal of Molecular Medicine, vol. 28, no. 1, pp. 115-119, 2011.

[12] B. Salaun, I. Coste, M. Rissoan, S. J. Lebecque, and T. Renno, "TLR3 can directly trigger apoptosis in human cancer cells," Journal of Immunology, vol. 176, no. 8, pp. 4894-4901, 2006.

[13] M. Y. Ahn, S. M. Kwon, H. H. Cheong et al., "Toll-like receptor 7 agonist, imiquimod, inhibits oral squamous carcinoma cells through apoptosis and necrosis," Journal of Oral Pathology and Medicine, vol. 41, pp. 540-546, 2012.

[14] A. Paone, D. Starace, R. Galli et al., “Toll-like receptor 3 triggers apoptosis of human prostate cancer cells through a PKC- $\alpha$ dependent mechanism," Carcinogenesis, vol. 29, no. 7, pp. 13341342, 2008.

[15] C. Maletzki, U. Klier, W. Obst, B. Kreikemeyer, and M. Linnebacher, "Reevaluating the concept of treating experimental tumors with a mixed bacterial vaccine: Coley's Toxin," Clinical and Developmental Immunology, vol. 2012, Article ID 230625, 15 pages, 2012.

[16] C. Maletzki, M. Gock, U. Klier, E. Klar, and M. Linnebacher, "Bacteriolytic therapy of experimental pancreatic carcinoma," World Journal of Gastroenterology, vol. 16, no. 28, pp. 3546-3552, 2010.

[17] S. Patyar, R. Joshi, D. S. P. Byrav, A. Prakash, B. Medhi, and B. K. Das, "Bacteria in cancer therapy: a novel experimental strategy," Journal of Biomedical Science, vol. 17, no. 1, article 21, 2010.

[18] C. Maletzki, M. Linnebacher, B. Kreikemeyer, and J. Emmrich, "Pancreatic cancer regression by intratumoural injection of live Streptococcus pyogenes in a syngeneic mouse model," Gut, vol. 57, no. 4, pp. 483-491, 2008.

[19] M. Linnebacher, C. Maletzki, J. Emmrich, and B. Kreikemeyer, "Lysates of S. pyogenes serotype M49 induce pancreatic tumor growth delay by specific and unspecific antitumor immune responses," Journal of Immunotherapy, vol. 31, no. 8, pp. 704713, 2008.

[20] M. Q. Wei, K. A. O. Ellem, P. Dunn, M. J. West, C. X. Bai, and B. Vogelstein, "Facultative or obligate anaerobic bacteria have the potential for multimodality therapy of solid tumours," European Journal of Cancer, vol. 43, no. 3, pp. 490-496, 2007.

[21] J. Park, D. Jeon, H. Yoon et al., "Poly I:C inhibits cell proliferation and enhances the growth inhibitory effect of paclitaxel in oral sqaumous cell carcinoma," Acta Odontologica Scandinavica, vol. 70, no. 3, pp. 241-245, 2012.

[22] M. Igartua and J. L. Pedraz, “Topical resiquimod: a promising adjuvant for vaccine development?" Expert Review of Vaccines, vol. 9, no. 1, pp. 23-27, 2010.

[23] E. Celis, "Toll-like receptor ligands energize peptide vaccines through multiple paths," Cancer Research, vol. 67, no. 17, pp. 7945-7947, 2007.

[24] B. Jin, T. Sun, X. H. Yu, Y. X. Yang, and A. E. Yeo, “The effects of TLR activation on T-cell development and differentiation," Clinical and Developmental Immunology, vol. 2012, Article ID 836485, 32 pages, 2012.

[25] T. Kaisho and S. Akira, "Regulation of dendritic cell function through toll-like receptors," Current Molecular Medicine, vol. 3, no. 4, pp. 373-385, 2003.
[26] T. Meyer and E. Stockfleth, "Clinical investigations of toll-like receptor agonists," Expert Opinion on Investigational Drugs, vol. 17, no. 7, pp. 1051-1065, 2008.

[27] E. Furrie, S. Macfarlane, G. Thomson, and G. T. Macfarlane, "Toll-like receptors-2, -3 and -4 expression patterns on human colon and their regulation by mucosal-associated bacteria," Immunology, vol. 115, no. 4, pp. 565-574, 2005.

[28] J. Kluwe, A. Mencin, and R. F. Schwabe, "Toll-like receptors, wound healing, and carcinogenesis," Journal of Molecular Medicine, vol. 87, no. 2, pp. 125-138, 2009.

[29] S. Rajput, L. D. Volk-Draper, and S. Ran, "TLR4 is a novel determinant of the response to paclitaxel in breast cancer," Molecular Cancer Therapeutics, vol. 12, no. 8, pp. 1676-1687, 2013.

[30] J. Bohnhorst, T. Rasmussen, S. H. Moen et al., "Toll-like receptors mediate proliferation and survival of multiple myeloma cells," Leukemia, vol. 20, no. 6, pp. 1138-1144, 2006.

[31] H. Bao, P. Lu, Y. Li et al., "Triggering of toll-like receptor-4 in human multiple myeloma cells promotes proliferation and alters cell responses to immune and chemotherapy drug attack," Cancer Biology and Therapy, vol. 11, no. 1, pp. 58-67, 2011.

[32] D. P. O'Leary, L. Bhatt, J. F. Woolley et al., "TLR-4 signalling accelerates colon cancer cell adhesion via NF- $\kappa \mathrm{B}$ mediated transcriptional up-regulation of Nox-1," PLoS ONE, vol. 7, Article ID e44176, 2012.

[33] S. H. Rhee, E. Im, and C. Pothoulakis, "Toll-like receptor 5 engagement modulates tumor development and growth in a mouse xenograft model of human colon cancer," Gastroenterology, vol. 135, no. 2, pp. 518-528, 2008.

[34] X. Zhao, M. Ai, Y. Guo et al., "Poly I: C-induced tumor cell apoptosis mediated by pattern-recognition receptors," Cancer Biotherapy and Radiopharmaceuticals, vol. 27, pp. 530-534, 2012.

[35] T. Meyer, C. Surber, L. E. French, and E. Stockfleth, "Resiquimod, a topical drug for viral skin lesions and skin cancer," Expert Opinion on Investigational Drugs, vol. 22, pp. 149-159, 2013.

[36] C. Bourquin, C. Hotz, D. Noerenberg et al., "Systemic cancer therapy with a small molecule agonist of toll-like receptor 7 can be improved by circumventing TLR tolerance," Cancer Research, vol. 71, no. 15, pp. 5123-5133, 2011.

[37] N. Tsavaris, C. Kosmas, M. Vadiaka, P. Kanelopoulos, and D. Boulamatsis, "Immune changes in patients with advanced breast cancer undergoing chemotherapy with taxanes," British Journal of Cancer, vol. 87, no. 1, pp. 21-27, 2002.

[38] U. Klier, C. Maletzki, B. Kreikemeyer, E. Klar, and M. Linnebacher, "Combining bacterial-immunotherapy with therapeutic antibodies: a novel therapeutic concept," Vaccine, vol. 30, no. 17, pp. 2786-2794, 2012.

[39] U. Klier, C. Maletzki, N. Göttmann, B. Kreikemeyer, and M. Linnebacher, "Avitalized bacteria mediate tumor growth control via activation of innate immunity," Cellular Immunology, vol. 269, no. 2, pp. 120-127, 2011.

[40] M. A. Geller and J. S. Miller, "Use of allogeneic NK cells for cancer immunotherapy," Immunotherapy, vol. 3, no. 12, pp. 14451459, 2011.

[41] M. A. Geller, S. Cooley, P. A. Argenta et al., "Toll-like receptor-7 agonist administered subcutaneously in a prolonged dosing schedule in heavily pretreated recurrent breast, ovarian, and cervix cancers," Cancer Immunology, Immunotherapy, vol. 59, no. 12, pp. 1877-1884, 2010.

[42] S. Adams, “Toll-like receptor agonists in cancer therapy," Immunotherapy, vol. 1, no. 6, pp. 949-964, 2009. 
[43] M. Ikeguchi, Y. Arai, Y. Maeta, K. Ashida, K. Katano, and T. Wakatsuki, "Topoisomerase i expression in tumors as a biological marker for CPT-11 chemosensitivity in patients with colorectal cancer," Surgery Today, vol. 41, no. 9, pp. 1196-1199, 2011.

[44] M. Rehli, "Of mice and men: species variations of Toll-like receptor expression," Trends in Immunology, vol. 23, no. 8, pp. 375-378, 2002.

[45] H. Lu, W. M. Wagner, E. Gad et al., "Treatment failure of a TLR-7 agonist occurs due to self-regulation of acute inflammation and can be overcome by IL-10 blockade," Journal of Immunology, vol. 184, no. 9, pp. 5360-5367, 2010. 


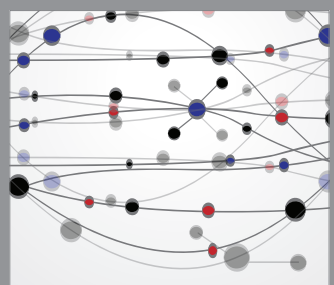

The Scientific World Journal
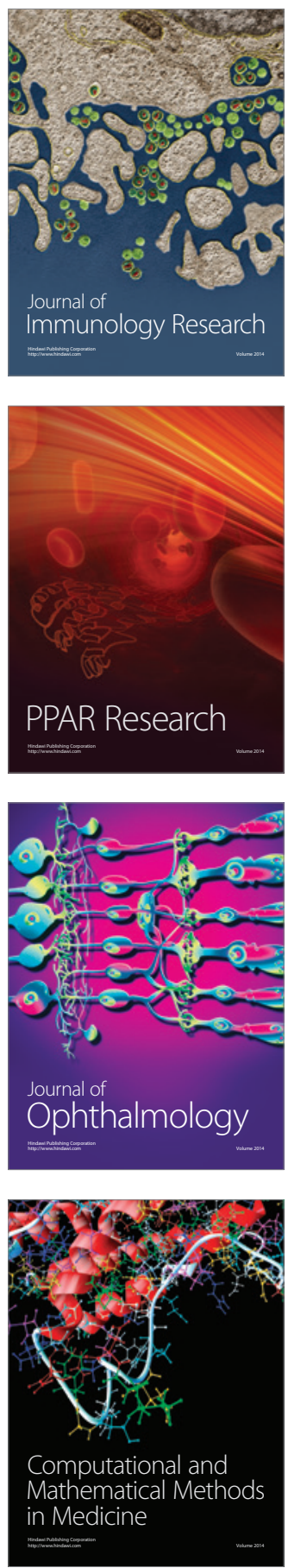

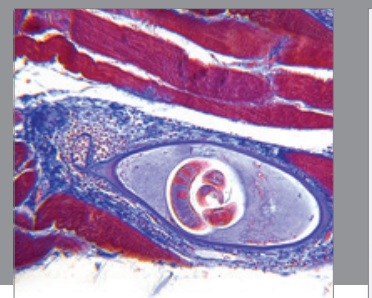

Gastroenterology

Research and Practice
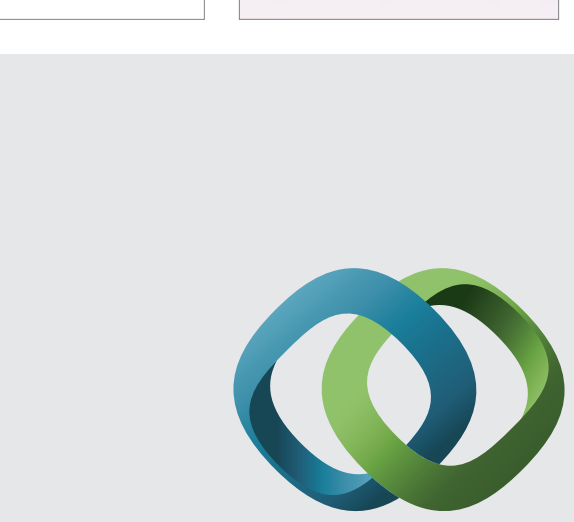

\section{Hindawi}

Submit your manuscripts at

http://www.hindawi.com
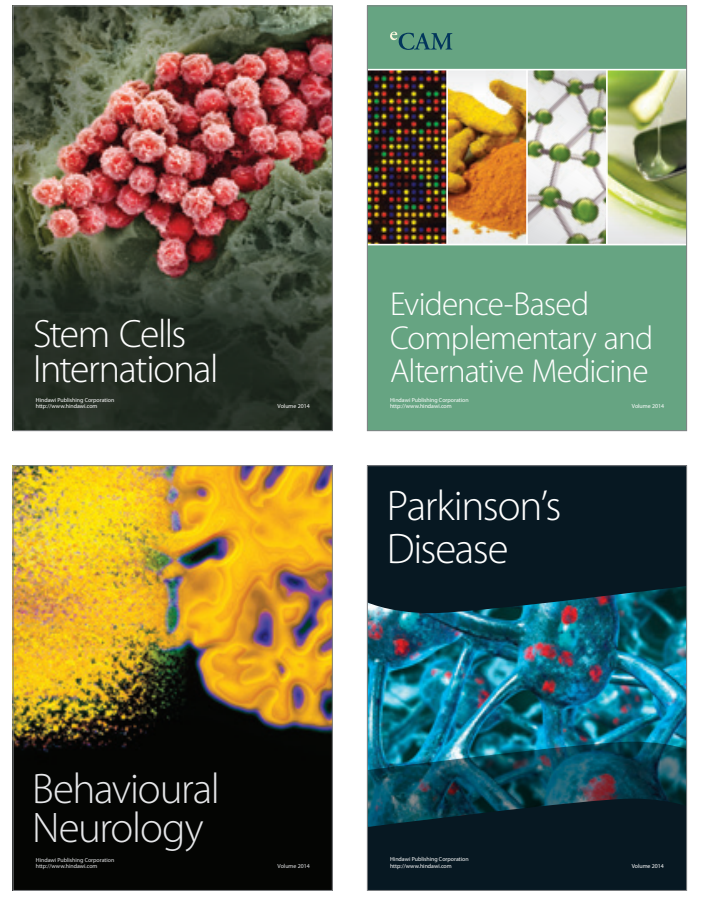
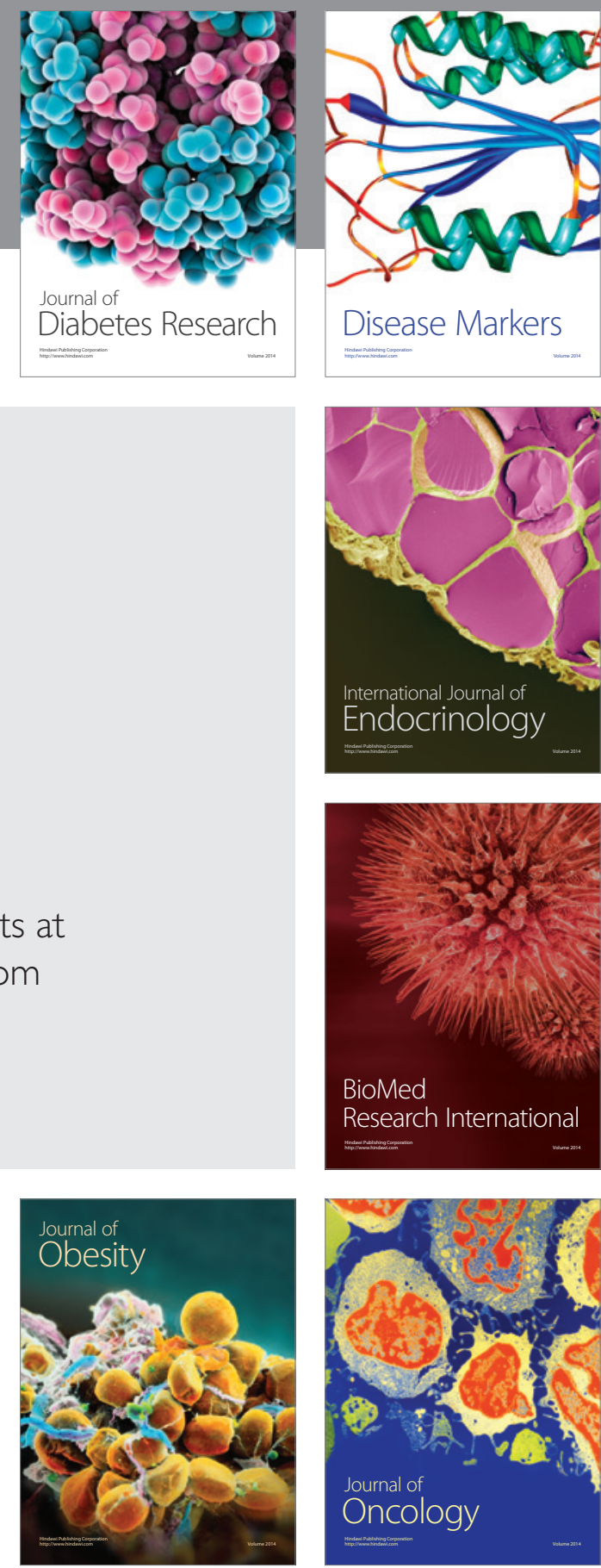

Disease Markers
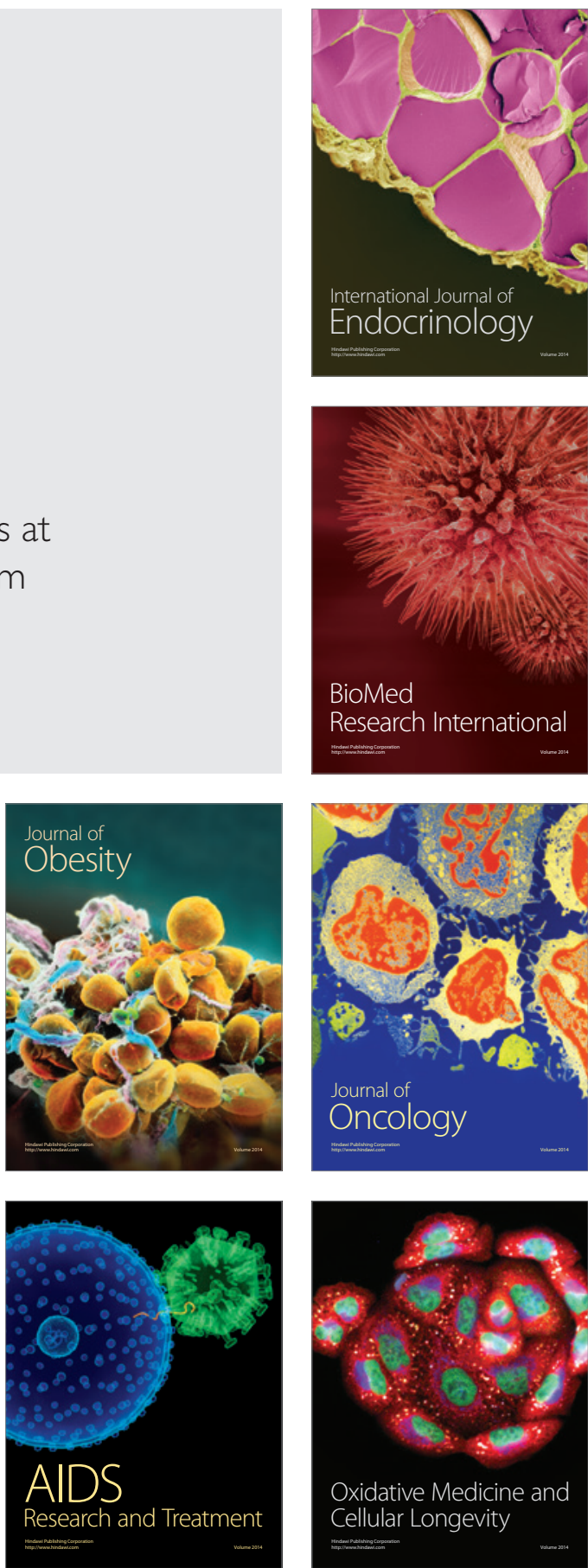